\title{
Retinoblastoma cT4 TNM Finding v7
}

National Cancer Institute

\section{Source}

National Cancer Institute. Retinoblastoma CT4 TNM Finding v7. NCI Thesaurus. Code C88764.

Extraocular disease detected by imaging studies. (from AJCC 7th Ed.) 